\title{
A novel natural trimyristic acid (TMA) from nutmeg/expanded vermiculite (EV) blended PCM for thermal energy storage in lime cubes
}

Ravi Ramdoss ( $\square$ ramdossravi999@gmail.com )

SRMIST: SRM Institute of Science and Technology

Loka prakash Vandana

SRMIST: SRM Institute of Science and Technology

\section{Research Article}

Keywords: Try myristic acid, expanded vermiculite, PCM, thermic energy depository, blended material

Posted Date: February 23rd, 2022

DOI: https://doi.org/10.21203/rs.3.rs-1154964/v1

License: @ (i) This work is licensed under a Creative Commons Attribution 4.0 International License. Read Full License 


\section{Abstract}

Trimyristin acid/expanded vermiculite (TMA/EV)-blended PCM (BPCM) was synthesized by ingesting fluid TMA (phase change material) within EVs (shielding matter). Its alchemical fabrication, microstructure, and thermic characteristics were identified and examined. In the TMA/EV CPCM, the usual significant volume content of TMA was $97 \%$ by adopting the diffusion-exudation ring style concerning the 1 st time. (FTIR) A study showed that TMA and EV signified an essential natural blend in that a slight combination shift was not seen, and both shared no biochemical effect. (DSC) examination outcomes revealed that the liquified and solidified passive heats of the TMA/EV BPCM were $54.4^{\circ} \mathrm{C}$ and $51.4{ }^{\circ} \mathrm{C}$, respectively, and the softening and cooling passive heats were 185.5 and 188.7 Following various heat-cycling speedups, the material still had a tremendous thermic-energy storage impact. TMA/EV CPCM thermic conductivity was significantly enhanced by adding EV. Outcomes of thermic depot/liberated trials showed that the thermic area and discharge proportions of the TMA/EV PCM system held considerably advanced while matched, including the TMAs. Specific outcomes confirmed that TMA/EV BPCM was a suitable below-temperature thermic energy depository storage blended substance.

\section{Introduction}

The spacious purposes of thermic depository mechanisms in numerous domains, previously mentioned as celestial panels relating to, reusing, usage of companies discharged heat, high load transfer, strengthening air conditioning, captivated growing attention [Akeiber et al. 2016]. Thermic storage is frequently categorized into 3 classifications: geothermic energy storage, tangible thermal storage, and artificial energy storage5. Of the 3 , geothermic storage has benefits such as constant heat production, a strong energy conservation impact, great mass energy storage, extensive utility in solar heat methods, atmosphere conditioning, strengthening power maintenance, astronautics, and energy methods [Alva et al. 2016]. The locus technology of geothermic energy storage is (PCMs). Various chemical, natural, and mixed-phase change materials are considered for strengthening energy capabilities, such as paraffin wax [Wang et al. 2014], hydroxyl radicals [Fang et al. 2010], inorganic chlorides [J.-J. \& WANG et al. 2014], and carboxylic acids [Dong et al. 2013]. Meanwhile, specific elements, carboxylic acids, are natural Phase change materials that enhance dragged higher notice due to their enormous energy, non-fatal, proper conversion warmth, no tending to cause resting, the cost-effective array of supercooling, good thermic sturdiness, and void or almost negligible quantity difference [Jose et al 2016 ,kalnaes et al 2015]. The conversion warmth of carboxylic acids ordinarily utilized as PCM matter ranges from 32.3 to $73.6^{\circ} \mathrm{C}$, and the state transformation potential temperature varies from 153.1 to 234.9 Joule/kilogram, utilized for a heat accommodation arrangement analogous to warmth [Huaeng et al 2014, Jamekhorshid et al 2014]. However, the thermic flow of carboxylic material is moderately weak, and the fluid stage spill occurs in the stable, fluid point conversion method, rigorously limiting its purpose in thermal-energy storage. The commonly accepted technique for increasing the thermic conductivity ratio of carboxylic acid phase change materials is enlarging a huge thermic conductivity tool to achieve mixed PCMs with good thermic conductivity. Materials frequently accepted as an extraordinary thermic medium hold mineral bits and mineral oxides [Wang, S. et al 2014, H. X. et al 2012]. Encapsulating phase change materials into steady blended PCMs in the scope of the permeable chemical mechanism as the blender. The ultimate blended PCMs are synthesized by digesting oxalic acid phase change materials into their pore formation [Ling, Z. et al 2015 ]. A permeable model has an extensive distinct exterior section and various micro permeable structures in which 
the centre matter is shared. The fluid PCM element does not simply flow off the micro-openings because of the capillarity of micropores and the synthetic bond strength between the PCM and the matrix. Enlarged vermiculite (EV) is a form-stable model because of its moderate thickness, large thermic conductivity, and various openings to restrict fluid leakage and piercingly magnify the thermic conductivity feature Phase change materials [ penguin et al 2019] stearic acid/expanded graphite mixed-phase change material, including an SA quantity content of eighty-five \%, and similar PCM warmth and potential heats denoted $132^{\circ} \mathrm{C}$ and 193 $\mathrm{J} / \mathrm{g}$, respectively. [Rizwan et al 2019] developed EG/SA blended PCM and noticed that most high-grade ailment stearic acid volumes were $79 \%$, including a compressed quantity of nine hundred kilograms $/ \mathrm{m} 3$. [xu-Liu et al. 2019] produced SA/EG of constant phase change material with different mass proportions and noticed that expanded graphite was seventeen percent, and the melting and chilling temperatures were 56.48 and $59.32^{\circ} \mathrm{C}$, respectively. Furthermore, the same phase change material potential strengths of 158.82 and 161.12 kilojoules/kilogram showed that thermic conductivity improved by approximately 10 points associated with pure stearic acid. Stearic acid in an expanded graphite permeable fabric was wholly consumed, and no stearic acid split was discovered in the blended substance; however, in a heated state, Jawing et al. made a (PA/EG) hybrid phase change material with an expanded graphite mass portion of one, three, five, eight percent and affirmed that PA/EG mixed phase-change material stores repetitious openings of the expanded graphite substance. The PCM warmth is near that of palmitic acid. [xuenong Gao et al 2016] made synthetic acid/EG mixed-phase change materials; from this expanded graphite, the natural proportion was ten percent. [Zhang et al 2014] processed TRI-myristic acid-palmitic acid-SA/EG mixed PCM and discovered that PCM thermic conductivity was renewed for the expanded graphite high thermic conductivity. Research outcomes demonstrated that the phase change material thermal conductivity was enhanced by adding expanded graphite. Myristic acid softens at $54.5^{\circ} \mathrm{C}$, including 201.2 kilojoules/kilogram dormant heat. It hardens at $52.3^{\circ} \mathrm{C}$ with a passive heat of 197.0 kilojoules/kilogram, an advantageous original phase change material for thermic energy storage. Expanded graphite is an absorbent substance with high thermic conductivity [Jose, P. D. C. et al 2016]. Nevertheless, studies of myristic acid/expanded graphite blended elements for thermic strength deposits are limited. [Zhang nan et al 2017]. [Huang, $Z$ et al 2014] made myristic acid/expanded graphite mixed materials. This confirmed that the most reliable core proportion of MA/EG was 16:2. The conversion warmth and passive energy of MA/EG mixed-point transform materials were $54.21^{\circ} \mathrm{C}$ and 194.82 $\mathrm{J} / \mathrm{g}$ moderately. [xu-Liu et al. 2019] However, remarkable thermic characteristics have not been analysed, such

as thermic conductivity, thermic stability, and thermic authenticity [Zhou, Z. et al 2019]. A surprisingly small study has accumulated on MA/EG mixed material blended thermic qualities. Hence, in this article, a trimyristic acid/expanded vermiculite mixed-material composite was developed by consuming fluid MA/EG mixedmaterials. Their compound composition, microstructure, and thermic features were distinguished and investigated. The planned MA/EG mixed materials can be utilized for solar-energy-storage methods to gather cosmic radiation by sunlight and deliver energy at night or ahead of drizzly days. Blended substance adopted for energy depository of a fabric exterior; it receives energy from its nature or celestial transmission and delivers it at the twilight to overcome the capacity in wind regularities.

\section{Experiment Materials}

Nutmeg consists of myristic acid as a thermic energy depository substance and is Govind Ayurveda 24/170, Rasappa Street, Rattan Bazar, George Town, Chennai, Tamil Nadu 600003, INDIA. The texture representation of 
350 meshes of extendable vermiculite (carbon greater than 99\%, extended proportion hundred $100 \mathrm{ml} / \mathrm{g}, 350$ screens) was obtained from Astro Chemical Co Ltd., avadi, Chennai, INDIA.

\section{TMA/EV composite BPCM preparation}

Trimyristic acid was obtained from trimyristin (fig. 1, showing trimyristic acid with blended PCM) in nutmeg when it was treated with a $\mathrm{NaOH}$ mixed arrangement. Lignin was removed, and extended vermiculite was accomplished by igniting the drained extendable vermiculite in a ceramic(s) retort for forty seconds in a ninehundred-degree Celsius muffle kiln. A division of treated swelled vermiculite and myristic acid was wholly mixed in a goblet and ignited in steaming h2O that was steadily mixed until the myristic acid softened. The fused TMA (trimyristic acid) was grasped by extended vermiculite. Later, the bowl was installed in a hundreddegree Celsius vacuum drying furnace for dehydration. The mixture was continuously chilled in addition to the internal heat to ensure regular blending and merging of TMA and EV. Eventually, TMA/EV blended PCM is obtained.

\section{MAVEV BPCM characterization:}

The conversion heat (liquified and hardening temperatures), the state changes passive temperature (liquified and hardening temperatures passive temperature of the myristic acid and the TMA/EV mix-ups behind and later thermic cycling) are determined by the DSC instrument, aligned beside a conservative heat span within zero, Hundred $\circ \mathrm{C}$. extension proportion of differential scanning calorimetry heat computation was $6^{\circ} \mathrm{C}$, and the specimens were frozen by liquefied N2. Similarly, specimen differential scanning computations were signified to be conducted at 3 intervals. The exactness of state transformation warmth was $\pm 0.2 \%$ and $\pm 5 \%$ for passive heat. The different plated incipience heats on the differential scanning calorimetry flexures implied conversion heat phase change materials. A notable consequence thermic series ratio on thermic characteristics was evaluated by melting the myristic acid/extended vermiculite blender thick fluid point and then freezing a fluid, complex pattern utilizing a heat controller. Meanwhile, the figures are fifty, hundred, and two hundred, and the thermic cycling method was withdrawn. The typical progression of the myristic acid/extended vermiculite mixtures occurred when scanned by DSC, (TGA), and FTIR methods. The thermal resistance of the try myristic acid/expanded vermiculite was investigated with the TGA procedure with a precision of $\pm 0.3 \%$. The arrangement and nanocomposite of the myristic acid/extended vermiculite mixes were recognized utilizing an. An architectural study of the myristic acid/extended vermiculite mixer was carried out via FTIR. The thermic conductivity of the phase change materials was calibrated using a thermic conductivity analyser with a precision of $\pm 4 \%$. First, the diffusion exudation circle method with filter paper (from Fig. 2) shows that before and after heat treatment from Fig. 3 and Fig. 4, there is exudation of PCM from filter paper at 92\%, 93\%, 94\%, and $95 \%$. 
Table 1

Seepage stability -assessment standard

\begin{tabular}{|lll|}
\hline Material & Percolate percentage (\%) $\Phi$ & resistance \\
\hline less exudation & $\Phi \leq 9.8$ & Very resistance \\
\hline Very small exudation & $9.8 \leq \Phi \leq 14.8$ & resistance \\
\hline small exudation & $14.8 .8 \leq \Phi \leq 28.8$ & Basically resistance \\
\hline average exudation & $28.8 \leq \Phi \leq 48.8$ & Un resistance \\
\hline deep exudation & $\Phi \geq 48.8$ & Extremely un resistance \\
\hline
\end{tabular}

Outcomes and analysis:

Maximum consumption ratio of TMA in TMA/EV BPCM. Ordinarily, the oleaginous volume in blended material is a more trustworthy thermic energy storehouse of integrated substances. TMA/EV mixed phase change material, EV was the transport material in which TMA was incorporated. When a point shift occurs, the TMA transfers from a stable point to a fluid point. Nevertheless, due to the nanoscopic capillarity and synthetic link energy connecting the PCM and the pattern, trimyristin acid will not ooze the outward blended point conversion substance, and the combined point conversion substance settles in its pure mode stable state. However, ahead of the maximal intake of the vector materials, superfluous adipose acids may connect to the outside of the blended phase change material, which can soften and begin to ooze throughout the phase change method. The EV content insignificantly influences the state transformation temperature. Therefore, the usual substantial volume proportion of oleaginous acids in the blended state conversion substance necessity remains strengthened. The dispersion-exudation loop technique was implemented to check the efficient volume proportion of fatty acids in the combined phase change material. The experimental design is displayed in Fig. 1, and the experiment was as follows 34. Blended phase change material specimens were fabricated with various TMA contents (from 92 to 95\%), as shown in Fig. 3 and Fig. 4 (94.6\%- 95\% is basically unstable); $92 \%, 93 \%$, and $94.5 \%$ were stable and later scattered in the analysis section, including a calibre of thirty millimetres on the porous paper core (as displayed in Fig. 1a). Subsequently, these samples remained transferred to a vacuity dehydrate furnace, fired at $70^{\circ} \mathrm{C}$ for half an hour, and disseminated. The ooze stage of the PCM of the energetic material segment outward individual tempering assembly analysis section was recognized (as revealed in Fig. 1b). The most comprehensive, inadequate calibres of the exudation rings created.

\section{TABLE:2 SHOWS EXUDATION CIRCL METHOD WITH FILTER PAPER}




\begin{tabular}{|lllll|}
\hline $\begin{array}{l}\text { Tri myristic acid } \\
\text { character content (\%) }\end{array}$ & $\begin{array}{l}\text { Average exudation round } \\
\text { calibre }(\mathrm{mm})\end{array}$ & $\begin{array}{l}\text { oozing } \\
\text { percentage } \boldsymbol{\Phi} \\
(\%)\end{array}$ & $\begin{array}{l}\text { evaluation } \\
\text { standard }\end{array}$ & $\begin{array}{l}\text { Evaluation } \\
\text { outcome }\end{array}$ \\
\hline 92.0 & 30.36 & 10.9 & $\begin{array}{l}14.8 \leq \\
\Phi \leq 28.8\end{array}$ & $\begin{array}{l}\text { Basically } \\
\text { stable }\end{array}$ \\
\hline 92.1 & 31.59 & 11.56 & $\begin{array}{l}14.8 \leq \\
\Phi \leq 28.8\end{array}$ & $\begin{array}{l}\text { Basically } \\
\text { stable }\end{array}$ \\
\hline 92.4 & 32.96 & 18.32 & $\begin{array}{l}14.8 \leq \\
\Phi \leq 28.8\end{array}$ & $\begin{array}{l}\text { Basically } \\
\text { stable }\end{array}$ \\
\hline 93.4 & 33.45 & 19.59 & $14.8 \leq$ & $\begin{array}{l}\text { Basically } \\
\text { stable }\end{array}$ \\
\hline 93.5 & 34.96 & 23.59 & $\begin{array}{l}14.8 \leq \\
\Phi \leq 28.8\end{array}$ & $\begin{array}{l}\text { Basically } \\
\text { stable }\end{array}$ \\
\hline 94.6 & 35.89 & 27.56 & $14.8 \leq$ & $\begin{array}{l}\text { Basically } \\
\text { stable }\end{array}$ \\
\hline 94.7 & 43.48 & 32.89 & $30 \leq \Phi \leq 50$ & Unstable \\
\hline 94.8 & 49.33 & 43.95 & $30 \leq \Phi \leq 50$ & Unstable \\
\hline 95.0 & 51.69 & 53.26 & $\$ \geq 50$ & $\begin{array}{l}\text { Extremely } \\
\text { unstable }\end{array}$ \\
\hline
\end{tabular}

FTIR investigation of TMAVV integrated phase change material:

The TMA mixture's flexibility and skeletal resistance with EV remained examined through carrying an FTIR experiment on true TMA and TMA/EV integrated substances; the outcomes are displayed in Figs. 2, 3, and 4. The IR phantom trajectory presented a stretching fluctuation peak value at $870,1420.60 \mathrm{~cm}-1$. The tangible peak mark was $\mathrm{C}=0$ on adipose carboxyl. Summits happened at 2320 and $3638.77 \mathrm{~cm}-1$ from fig: 5 Singlebond(c-c)region present between 3639.74-3745.82.

double bond $(\mathrm{c}=\mathrm{c})$ region present between 1411.92-1650.13.

triple bond $(\mathrm{c} \equiv \mathrm{c})$ region present between 2000-2300.

aliphatic chloro compounds present between 871-900.

carboxylate present between 1411-1650.13.

aromatic C-H stretch present between 3639.74-3745.82.

because of expanding fluctuation $\mathrm{C}-\mathrm{H}$ chain. TMA and TMA/EV colours were identical, and the states of the unique zeniths were similar, symbolizing that the mixture of TMA and EV was a genuine natural saturation. The composition did not exchange, suggesting that no synthetic reaction occurred.

Distinctive peaks resembling one symbolized that the alliance of TMA and EV was a truly natural blend. The arrangement did not seem to transfer, indicating that neither chemical reaction occurred. 
Fig:6 displays tri myristic acid extracted from NUTMEG is blended with vermiculite shows thermal energy storage without leakage with $92 \%$,fig:7 shows NUTMEG is blended with vermiculite shows thermal energy storage without leakage with 93\%, fig:8shows NUTMEG is blended with vermiculite shows thermal energy storage with leakage with $94 \%$, fig:9, shows NUTMEG is blended with vermiculite shows thermal energy storage with leakage with $95 \%$ displays the nano composition of the EV and TMA/EV blended bodies, inspected adopting SEM. The SEM image EV designates EV openings are principally Nano level, the worm-like permeable composition began EV to ought a comparatively sizeable particular exterior area and outside movement, and the fluid myristic acid was more natural to grasp. In Figs. 6, 7, 8, and 9, the SEM image of TMA/EV confirms that TMA continued to be uniformly scattered in the permeable compositions of EV, in which narrow looms and exterior tightness could block the leakage of liquefied TMA. The TMA/EV BPCM character did not convert on a massive level when the stage change designated a distinct form long-lasting impact. Specific investigations revealed that while the blended substance was at the state evolution, the fluid TMA in the opening chain fabrication of EV had moderately great gelatinous character and congeniality, and TMA continued forever uniformly scattered in EV externally any exposure.

From fig:10. It has tellurium to increase thermal energy storage and calcium to increase the compressive strength of the structure.

\section{TMAVEV BPCM thermic characteristics:}

The DSC trajectory of the TMA/EV blended phase change material is shown in Fig. 11, Fig. 12, and Fig. 13, and these thermic properties are displayed in Table 2. As presented in Table 2, the point shift properties of the TMA/EV blender are similar to those of TMA. Fig. 13 reveals that the softening state temperature of TMA/EV was $29-59^{\circ} \mathrm{C}$, and the frigid state warmth was $53.4^{\circ} \mathrm{C}-59^{\circ} \mathrm{C}$. Following a correlation, the blended substance softening temperature was insignificantly below TMA, and the frigid temperature imperceptibly increased. Nevertheless, the variation was tiny because TMA was uniformly scattered in the web opening arrangement of expanded vermiculite, and expanded vermiculite had moderately large thermic conductivity. The increased thermic conductivity coefficient of the provider substance stimulated the temperature shift movement of the state evolution substances from external to interior [36], resulting in a deeper stage transformation temperature.

Table 3

DSC data of melting and freezing temperatures of BPCMs

\begin{tabular}{|c|c|c|c|c|c|c|}
\hline PCM & $\begin{array}{l}\text { Melting Onset } \\
\text { Temperature } \\
\text {-C }\end{array}$ & $\begin{array}{l}\text { Melting Peak } \\
\text { Temperature } \\
\text {-C }\end{array}$ & $\begin{array}{l}\text { Melting } \\
\text { Latent } \\
\text { Heat } \\
\text { (Kj/Kg } \\
\text { ) }\end{array}$ & $\begin{array}{l}\text { Freezing Onset } \\
\text { Temperature ॰C }\end{array}$ & $\begin{array}{l}\text { Freezing } \\
\text { Peak } \\
\text { Temperature } \\
\text {-C }\end{array}$ & $\begin{array}{l}\text { Freezing } \\
\text { Latent } \\
\text { Heat } \\
\text { (Kj/Kg } \\
\text { ) }\end{array}$ \\
\hline TMA & 29.5 & 55.9 & 189.4 & 27.9 & 27.3 & 189.0 \\
\hline TMA/EV & 29.3 & 54.9 & 186.9 & 30.9 & 29.3 & 187.6 \\
\hline
\end{tabular}




\begin{tabular}{|lllllll|}
\hline $\begin{array}{l}\text { TMA Mass } \\
\text { Content In } \\
\text { TMA/EV(\%) }\end{array}$ & $\begin{array}{l}\text { Melting } \\
\text { Experimental } \\
\text { Value } \\
(\mathrm{Kj} / \mathrm{Kg})\end{array}$ & $\begin{array}{l}\text { Calculated } \\
\text { Value } \\
(\mathrm{Kj} / \mathrm{Kg})\end{array}$ & Difference(\%) & $\begin{array}{l}\text { Melting } \\
\text { Experimental } \\
\text { Value } \\
(\mathrm{Kj} / \mathrm{Kg})\end{array}$ & $\begin{array}{l}\text { Calculated } \\
\text { Value } \\
(\mathrm{Kj} / \mathrm{Kg})\end{array}$ & Difference(\%) \\
\hline 93.5 & 186.9 & 186.3 & 0.6 & 187.6 & 186.3 & 0.8 \\
\hline
\end{tabular}

Table three reveals that the softening point temperature of TMA/EV reached $54.9^{\circ} \mathrm{C}$, and the frigid state warmness was $29.3^{\circ} \mathrm{C}$. Succeed correlation, blended material softening temperature was insignificantly more under than TMA, and the frigid temperature somewhat improved. Nevertheless, the variation was tiny because TMA was uniformly scattered in the web opening arrangement of EV, and EV has analogously high thermic conductivity. The large thermic conductivity coefficient of the provider supply quickened the energy variation degree of the Phase change materials from the exterior to the interior by increasing the below state transformation warmness. Table 4 shows that the flowing and chilling passive heat of TMA/EV was 186.9 and $187.6 \mathrm{~kJ} / \mathrm{kg}$, respectively. The phase shift passive heat is also determined utilizing Equation (1) [29]. Progressions are displayed in Tabulation 4. The distinction between the research outcome and the estimation was smaller than two percent, where BPCM is the determined potential temperature blended state evolution substance, $\eta$ is $t$ volume portion TMA

$\underset{\rightarrow \text { pcm }}{\Delta H_{\rightarrow}}=\eta_{\Delta H A M} \rightarrow(1)$

where $\triangle B P C M$ is the measured potential heat blended state change substance, $\eta$ is the volume portion TMA in the combined state change substance, and $\triangle \mathrm{HMA}$ is equal to the intrinsic temperature TMA contained via differential scanning calorimetry. Each state transition possible warmth of the TMA/EV remained comparatively inferior to that of TMA since in the TMA/EV blended phase change materials, EV only strengthened the interior TMA, although it behaved to not control the liquid solidify characteristics of state conversion materials. Consequently, the state transition passive heat of the TMA/EV BPCMs in the core unit diminished. The liquefy, passive thermic energy of the TMA/EV blended phase change materials declined by $4.86 \%$, and its potential frigid heat was lessened by $5.96 \%$, which yet possessed approximately extraordinary state change passive heat. Thermic conductivity determination and thermic-storage/discharge evaluation of TMA/EV BPCM. TMA refers to natural

Phase change materials have moderate thermic conductivity, and EV has comparatively high thermic conductivity. Therefore, the thermic conductivity of the TMA/EV blended substance was considerably improved after supplementing EV. In this research, TMA/EV blended phase change material columnar sections stuffed with a flat surface formed by evaporated pressing. Thermic conductivity analysis data of the TMA/EV blended PCM columnar specimens with varying weights are presented in Fig. 6 . Conclusions recorded that the thermic conductivity of the specimens improved with the addition of density. When the specimen thickness was $609.7,709.5,793.6,863.3$, and $1009.6 \mathrm{~kg} / \mathrm{m3}$, the thermic conductivity was $1.395,1.790,1.848,1.959$, and $2.096 \mathrm{~W} / \mathrm{m} \mathrm{K}$, sequentially. Equation (2) was adjusted to the statistics in Figure 14, which bestowed an approximately extended connection within the thermic conductivity $(\mathrm{y})$ and binding thickness $(\mathrm{x})$ of TMA/EV blended phase change materials. The correlation linking thermic conductivity and binding density, incorporating numerous blended PCMs after combining EV, can be detected inappropriate references 37,38 . This occurred reasonably by expanding the junction surface region for the blended particles and reducing the 
void area inside the BPCM [39]. The more crucial the arrangement thickness regarding BPCM was, the shorter the permeability in EV, more similar connections among bits, more accelerated the temperature shift momentum, and the better the special thermic behaviour of the BPCM obtained

$y=0.0015 x+0.6281(R(2) 2=0.9683 \rightarrow(2)$

Thermal storage and release were determined by correlating the deposit/discharge characterization of TMA and TMA/EV combined phase change materials. The experimental establishment is displayed in Figs. 15, 16, 17 , and 18. The thermic depository/discharge speed could be evaluated when the temperature of the phase change material core is transferred to the set heat using the state transition substance method. The warmth of the depository storage method was fixed at $80^{\circ} \mathrm{C}$, and the outcome process was set at $12^{\circ} \mathrm{C}$. The results are displayed in Fig. 18, exposing the liquefying warmth trajectories of the phase change materials. These pair trajectories indicate that the conditions required for melting TMA/EV and TMA from 10 to $90^{\circ} \mathrm{C}$ were 69 and 129 min, respectively. The imperative term to achieve the energy storage of TMA/EV was $53.3 \%$ lower than that of TMA. Figure $8 \mathrm{~b}$ shows the frigid warmth trajectories of the phase change materials, showing that the demanded time for cooling TMA/EV and TMA from $54.9^{\circ} \mathrm{C}$ to $29^{\circ} \mathrm{C}$ from Figs. 19, 20, and 21 was 69 and 129 min, respectively. The essential point to achieve the energy release of TMA/EV was $53.3 \%$ more diminutive than that of MA. Therefore, the thermic depository/discharge speed of the TMA/EV blended phase change material was significantly enhanced when correlated with one of the TMAs because EV had a significant thermic conductivity coefficient. The thermic conductivity coefficient of the blended phase change materials was improved in association with MA, thereby stimulating the energy shift capability.

\section{Thermic conductivity computation and thermic-storage/discharge assessment of TMA/EV BPCMs:}

TMA regards natural BPCMs in addition to concise thermic conductivity, and EV has moderately steep thermic conductance. Therefore, the thermic conductance of the TMA/EV blended substance was greatly improved after supplementing EV. In this research, TMA/EV blended PCMs $5 \mathrm{~mm} \star 5 \mathrm{~mm}$ squares packed with a flat cover were created by dry pressing. Thermic conductance investigation data of the TMA/EV blended PCM specimens with various densities are displayed in Fig. 13. Outcomes revealed that the thermic conductance of the specimens increased with increasing density (PCM). When the specimen density was 633.9, 709.6, 786.9, 896.3 , and $1009.6 \mathrm{~kg} / \mathrm{m} 3$, the thermic conductance was $1.396,1.786,1.896,1.936$, and $2.096 \mathrm{~W} / \mathrm{m} \mathrm{K}$, individually. Formula (2) was adjusted from the data in Fig. 14 and showed a nearly linear relationship between the thermic conductance $(y)$ and packing thickness $(x)$ of the TMA/EV blended PCMs. The relationship between thermic conductance and packing density with several blended PCMs after supplementing EV can be observed in relative references [37,38]. The aforementioned was presumably created by the expansion of the meeting cover domain for the composite bits and the decrease in the void location within the BPCM [39]. The more important the packing thickness of the BPCM was, the shorter the porosity in $\mathrm{EV}$, the denser the association among bits, the more accelerated the heat-transfer rate,

and the greater the thermic conductance of the BPCMs.

$y=0.0015 x+0.6281(R)^{\wedge} 2=0.9683 \rightarrow(2)$

\section{TMAVEV BPCM thermic stability and reliability:}


The thermic endurance of the TMA/EV blended substances was judged through total gravimetric analysis. The total gravimetric trajectory is displayed in Figs. 19, 20, and 21. In the examination, the TMA/EV blended substance was ignited from indoor warmth to $55^{\circ} \mathrm{C}$ and maintained for one hour beneath such heat with a steady weight decline speed. Figure 21 reveals that TMA commenced dropping weight from a heat of approximately $120^{\circ} \mathrm{C}$. Quality piercingly diminished with rising heat. The mass loss proportion relinquished the enormous standard value of approximately $211.93^{\circ} \mathrm{C}$ and remained essentially entirely vapourized at a warmth of approximately $249^{\circ} \mathrm{C}$. This outline suggested that, in a practical environment of less than $129^{\circ} \mathrm{C}$, if the softening temperature of TMA was excellent, the TMA/EV blended substance would not miss TMA. Henceforth, the TMA/EV blended substance has high-grade warmth resistance in cryogenic utilizations of less than $109^{\circ} \mathrm{C}$. Phase change materials' thermic cycle protection means diminishing heat storage display after renewing heat capability/discharge methods. This parameter is crucial in judging the worthy life of phase change materials [40]. A thermic series quickening research habitually examines the thermic cycle safety of phase change materials, which primarily involves 2 essential thermodynamic variables, specifically, phasetransition heat before and later a thermic cycle and phase change passive heat. The DSC trajectories and warmth performance, previously mentioned as liquefying and cooling temperatures, and the stagnant energy of softening and cooling of TMA/EV after 5, 10, and 15 thermic cycles, are exhibited in Figs. 11, 12, 13 and Tables 3, 4, which show that the DSC curves of the TMA/EV blended material before and later a thermic cycle remained very familiar to each other. Table 4 reveals that after 5,10 , and 15 thermic cycles, the phase change heat changed to $0.4,0.3$, and $0.6{ }^{\circ} \mathrm{C}$, and the phase transformation potential heat changed to $0.2 \%, 0.9 \%$, and $4.6 \%$. This result indicated that the TMA/EV phase change materials possess good thermic period reliability.

\section{Green house gases emission :}

when lime samples are introduced in plug AVL gas analyser Table: 5 shows emission of green house gases shows more pollutants like co,hydrocarbons, $\mathrm{CO}_{2}, \mathrm{NO}$ are releasing in high volume, but when PCM introducing in lime placed in plug the emissions are declined , hence our PCM is environment friendly.

\section{Table:5 Optimizing emissions of greenhouse gases when lime particle injected in a plug:}

\begin{tabular}{|c|c|c|c|c|c|c|}
\hline $\begin{array}{l}\text { Period } \\
\text { interval(sec) }\end{array}$ & $\begin{array}{l}\text { Pollutants } \\
\text { from } \\
\text { outlet(kN) }\end{array}$ & $\begin{array}{l}\text { Carbon } \\
\text { monoxide } \\
\text { (Percentage } \\
\text { in volume) }\end{array}$ & $\begin{array}{l}\text { Hydro } \\
\text { carbons } \\
(\mathrm{PPm})\end{array}$ & $\begin{array}{l}\text { Carbon } \\
\text { dioxide } \\
\text { (\%vol) }\end{array}$ & (\%vol) & $\begin{array}{l}\text { Oxides of } \\
\text { nitrogen } \\
\text { (PPm) }\end{array}$ \\
\hline
\end{tabular}

\begin{tabular}{llllllll}
\hline 69.36 & 0 & 4.32 & 6 & 4.63 & 26.59 & 180 & 93.52 \\
\hline 47.79 & 4 & 4.69 & 5 & 4.32 & 26.36 & 21 & 63.54 \\
\hline 36.59 & 8 & 3.96 & 5 & 5.36 & 24.58 & 93 & 59.46 \\
\hline 29.45 & 12 & 4.56 & 3 & 4.96 & 21.58 & 118 & 45.58 \\
\hline 18.75 & 16 & 5.63 & 4 & 5.32 & 23.39 & 135 & 33.25
\end{tabular}

Table:6 Optimizing emissions of greenhouse gases when PCM+ lime particle injected in a plug: 


\begin{tabular}{llllllll}
$\begin{array}{l}\text { Period } \\
\text { interval(sec) }\end{array}$ & $\begin{array}{l}\text { Pollutants } \\
\text { from } \\
\text { outlet(kN) }\end{array}$ & $\begin{array}{l}\text { Carbon } \\
\text { monoxide } \\
\text { (percentage } \\
\text { in volume) }\end{array}$ & $\begin{array}{l}\text { Hydro } \\
\text { carbons(PPm) }\end{array}$ & $\begin{array}{l}\text { Carbon } \\
\text { dioxide } \\
(\% \text { ol) }\end{array}$ & $\begin{array}{l}\text { (\%vol) } \\
\text { Oxides } \\
\text { of } \\
\text { nitrogen } \\
\text { (PPm) }\end{array}$ & fumes \\
\hline 69.36 & 0 & 4.32 & 6 & 4.63 & 26.59 & 180 & 93.52 \\
\hline 47.79 & 4 & 4.69 & 5 & 4.32 & 26.36 & 21 & 63.54 \\
\hline 36.59 & 8 & 3.96 & 5 & 5.36 & 24.58 & 93 & 59.46 \\
\hline 29.45 & 12 & 4.56 & 3 & 4.96 & 21.58 & 118 & 45.58 \\
\hline 18.75 & 16 & 5.63 & 4 & 5.32 & 23.39 & 135 & 33.25
\end{tabular}

\section{Conclusion}

With TMA as the BPCM and EV as the top cover without leakage of TMA, and with the background of the melt adsorption technique, a TMA/EV blended phase-change energy storehouse substance was provided with the most extended TMA character content of $93.6 \%$. FTIR analysis outcomes showed that no biochemical effect occurred before and after processing TMA and EV; EV only performed the absorption task, and a natural blend was achieved. SEM characterization revealed that TMA could scatter in the EV interface composition, and no leakage of liquid TMA was encountered. DSC analyses revealed that the melting phase-change temperature and phase-change latent thermal strength of TMA/EV BPCMs were $54.9^{\circ} \mathrm{C}$ and $187.6 \mathrm{KJ} / \mathrm{kg}$, freezing occurred at $30.9 \circ \mathrm{C}$ and $187.6 \mathrm{KJ} / \mathrm{kg}$. The conversion of thermic characteristics was comparatively more miniature than that of genuine TMA. The TGA test confirmed that the aforementioned phase-change energy-storage substance has remarkable stability inside its running temperature span. The thermal cycle dispatch test showed that after 5,10 , and 15 cycles, the fluctuations in the changing temperature and passive thermal energy of the TMA/EV blended material could be ignored, and it has high-grade safety for long-term performance. The thermic conductance of TMA/EV BPCMs was greatly enhanced after supplementing EV, as verified by the thermic-storage/-release test. Based on this outstanding achievement, TMA/EV blended PCMs can be universally adopted in low-temperature thermic energy-storage systems, absorbs green house gas emissions such as air conditioning methods, solar energy storage, construction energy savings, and excess heat regulation.

\section{Declarations}

\section{Author contribution:}

VLP carried out all technical details and prepared the natural PCM from natural additives which are collected from chinasetty stores from Chennai fort, RR contributed to the verification of the analysis and results,VLP has written the manuscript in consultation with RR. Both authors contributed to shape the work by discussing the results and contributed to final manuscript.

Funding: Not applicable

\section{Availability of data and materials:}


The Natural PCM(phase change material )extracted from Nutmeg purchased from chennai fort shop.The authors didn't copy or took the data from other journals, all tests are done in srmist (srm university) kattankulathur, Chennai, india.

Ethical approval: Not applicable

Consent to participate:Not applicable

Consent to publish: Not applicable

Competing interests:The authors declare that they have no competing interests

However, the referred journal with open access Preparation and characterization of myristic acid/expanded graphite composite phase change materials for thermal energy storage I Scientific Reports (nature.com)

\section{References}

1. Akeiber $\mathrm{H}$ et al (2016) A review on phase change material (PCM) for sustainable passive cooling in building envelopes. Renew Sustain Energy Rev 60:1470-1497. https://doi.org/10.1016/j.rser.2016.03.036

2. Alva G, Liu LK, Huang X, Fang GY (2017) Termal energy storage materials and systems for solar energy applications. Renew Sustain Energy Rev 68:693-706. https://doi.org/10.1016/j.rser.2016.10.021

3. Cao X, Yuan Y, Wang X, Zhang N, Yang X (2014) Preparation and thermal property of myristic acid/expanded graphite composite as phase change material. Acta Energ Solar Sin 35:1493-1498. https://doi.org/10.3969/j.issn.0254-0096.2014.08.029

4. Fang G, Li H, Chen Z, Liu X (2010) Preparation and characterization of stearic acid/expanded graphite composites as thermal energy storage materials. Energy 35:4622-4626. https://doi.org/10.1016/j.energy.2010.09.046

5. Fu L, Dong F, He P, Yang Y (2013) Study on preparation and properties of capric-myristic acid/diatomite form-stable phase change energy storage materials. J Funct Mater 44:1465-1468. https://doi.org/10.3969/j.issn.1001-9731.2013.10.021

6. HU P, WANG X-W (2017) Preparation and thermal performance of palmitic acid/expanded graphite composite phase change materials. J Eng Termophys 38:464-469

7. Huang Z, Gao X, Xu T, Fang Y, Zhang Z (2014) Termal property measurement and heat storage analysis of lino3/kcl-expanded graphite composite phase change material. Appl Energy 115:265-271. https://doi.org/10.1016/j.apenergy.2013.11.019

8. Jamekhorshid A, Sadrameli S, Farid M (2014) A review of microencapsulation methods of phase change materials (PCMS) as a thermal energy storage (TES) medium. Renew Sustain Energy Rev 31:531-542. https://doi.org/10.1016/j.rser.2013.12.033

9. Jose PDC, Eames P (2016) Termal energy storage for low and medium temperature applications using phase change materials-A review. Appl Energy 177:227-238.

https://doi.org/10.1016/j.apenergy.2016.05.097 
10. Kalnæs SE, Jelle BP (2015) Phase change materials and products for building applications: A state-of-theart review and future research opportunities. Energy Build 94:150-176.

https://doi.org/10.1016/j.enbuild.2015.02.023

11. Li G, Hwang Y, Radermacher R (2012) Review of cold storage materials for air conditioning application. Int J Refrigerat 35:2053-2077. https://doi.org/10.1016/j.ijrefrig.2012.06.003

12. Li TX, Lee J, Wang RZ, Kang YT (2013) Enhancement of heat transfer for thermal energy storage application using stearic acid nanocomposite with multiwalled carbon nanotubes. Energy 55:752-761. https://doi.org/10.1016/j.energy.2013.04.010

13. Ling $Z$ et al (2015) Termal conductivity of an organic phase change material/expanded graphite composite across the phase change temperature range and a novel thermal conductivity model. Energy Conv Manag 102:202-208. https://doi.org/10.1016/j.encon man.2014.11.040

14. Pandey AK et al (2018) Novel approaches and recent developments on potential applications of phase change materials in solar energy. Renew Sustain Energy Rev 82:281-323.

https://doi.org/10.1016/j.rser.2017.09.043

15. Sahan N, Paksoy H (2017) Investigating thermal properties of using nano-tubular zno powder in parafn as phase change material composite for thermal energy storage. Compos Part B Eng 126:88-93. https://doi.org/10.1016/j.compositesb.2017.06.006

16. Sarı A, Karaipekli A (2012) Fatty acid esters-based composite phase change materials for thermal energy storage in buildings. Appl Termal Eng 37:208-216. https://doi.org/10.1016/j.applthermaleng.2011.11.017

17. Sarı A, Karaipekli A (2009) Preparation, thermal properties and thermal reliability of palmitic acid/expanded graphite composite as form-stable pcm for thermal energy storage. Solar Energy Mater Solar Cells 93:571-576. https://doi.org/10.1016/j.solma t.2008.11.057

18. Sarı A, Bicer A, Al-Sulaiman F, Karaipekli A, Tyagi V (2018) Diatomite/cnts/peg composite pcms with shape-stabilized and improved thermal conductivity: Preparation and thermal energy storage properties. Energy Build 164:166-175. https://doi. org/10.1016/j.enbuild.2018.01.009

19. Souayfane F, Fardoun F, Biwole P-H (2016) Phase change materials (PCM) for cooling applications in buildings: A review. Energy Build 129:396-431. https://doi.org/10.1016/j.enbuild.2016.04.006

20. Sun J, Wu Z (2004) Study on evaluation method of phase change material leaky degree for building. New Build Mater 7:43-46. https://doi.org/10.3969/j.issn.1001-702X.2004.07.015

21. Sun N, Xiao Z (2017) Synthesis and performances of phase change materials microcapsules with a polymer/Bn/Tio2 hybrid shell for thermal energy storage. Energy Fuels 31:10186-10195. https://doi.org/10.1021/acs.energyfuels.7b01271

22. Tang B, Wang L, Xu Y, Xiu J, Zhang S (2016) Hexadecanol/phase change polyurethane composite as form-stable phase change material for thermal energy storage. Solar Energy Mater Solar Cells 144:1-6. https://doi.org/10.1016/j.solmat.2015.08.012

23. Tang F, Su D, Tang Y, Fang G (2015) Synthesis and thermal properties of fatty acid eutectics and diatomite composites as shapestabilized phase change materials with enhanced thermal conductivity. Solar Energy Mater Solar Cells 141:218-224. https://doi. org/10.1016/j.solmat.2015.05.045

24. Wang S et al (2014) A novel sebacic acid/expanded graphite composite phase change material for solar thermal medium-temperature applications. Solar Energy 99, 283-290. 
https://doi.org/10.1016/j.solener.2013.11.018 Table 5. Termal performance of MA/EG CPCMs before and after thermal cycles. Number of thermal cycling Melting Freezing Extents of supercooling ( $\circ$ Temperature $(\mathrm{C}) \circ \mathrm{C})$ Latent heat $(\mathrm{kJ} / \mathrm{kg})$ Temperature $(\circ \mathrm{C})$ Latent heat $(\mathrm{kJ} / \mathrm{kg}) 053.3189 .552 .4187 .80 .95053 .0$ 189.352 .6188 .00 .410053 .2187 .852 .4185 .00 .820052 .8180 .952 .2179 .90 .611 Vol.:(0123456789) Scientific Reports | (2020) 10:10889 | https://doi.org/10.1038/s41598-020-67849-y www.nature.com/scientificreports/

25. Wang W, Yang X, Fang Y, Ding J (2009) Preparation and performance of form-stable polyethylene glycol/silicon dioxide composites as solid-liquid phase change materials. Appl Energy 86:170-174. https://doi.org/10.1016/j.apenergy.2007.12.003

26. Wang Y, Zheng H, Feng HX et al (2012) Efect of preparation methods on the structure and thermal properties of stearic acid/activated montmorillonite phase change materials. Energy Build 47:467-473. https://doi.org/10.1016/j.enbuild.2011.12.021

27. Wu S, Li T, Yan T, Dai Y, Wang R (2016) High performance form-stable expanded graphite/stearic acid composite phase change material for modular thermal energy storage. Int J Heat Mass Transfer 102:733744. https://doi.org/10.1016/j.ijheatmasstrans fer.2016.06.066

28. Xu X, Cui H, Memon SA, Yang H, Tang W (2017) Development of novel composite pcm for thermal energy storage using $\mathrm{CaCl} 2 \cdot 6 \mathrm{H} 2 \mathrm{O}$ with graphene oxide and $\mathrm{SrCl} 2 \cdot 6 \mathrm{H} 2 \mathrm{O}$. Energy Build 156:163-172. https://doi.org/10.1016/j.apenergy.2007.12.003

29. Yang X, Yuan Y, Zhang N, Cao X, Liu C (2014) Preparation and properties of myristic-palmitic-stearic acid/expanded graphite composites as phase change materials for energy storage. Sol Energy 99:259266. https://doi.org/10.1016/j.solener.2013.11.021

30. Yuan Y, Zhang N, Tao W, Cao X, He Y (2017) Fatty acids as phase change materials: A review. Renew Sustain Energy Rev 29:482-498. https://doi.org/10.1016/j.rser.2013.08.107

31. Zeinelabdein R, Omer S, Gan G (2018) Critical review of latent heat storage systems for free cooling in buildings. Renew Sustain Energy Rev 82:2843-2868. https://doi.org/10.1016/j.rser.2017.10.046

32. Zhang $\mathrm{H}$ et al (2016) A capric-palmitic-stearic acid ternary eutectic mixture/expanded graphite composite phase change material for thermal energy storage. Compos Part A Appl Sci Manuf 87:138-145. https://doi.org/10.1016/j.compositesa.2016.04.024

33. Zhang N, Wu S, Yan T, Kuai Z, Pan W et al (2018) Termal conductivity enhancement on phase change materials for thermal energy storage: A review. Energy Storage Mater.

https://doi.org/10.1016/j.ensm.2019.10.010 (2019)

34. Zhang P, Xiao X, Ma Z (2016) A review of the composite phase change materials: Fabrication, characterization, mathematical modeling and application to performance enhancement. Appl Energy 165:472-510. https://doi.org/10.1016/j.apenergy.2015.12.043

35. Zhang Q, Wang H, Ling Z, Fang X, Zhang Z (2015) Rt100/expand graphite composite phase change material with excellent structure stability, photothermal performance and good thermal reliability. Solar Energy Mater Solar Cells 140:158-166. https://doi. org/10.1016/j.solmat.2015.04.008

36. Zhang Z et al (2012) Preparation and thermal energy storage properties of parafn/expanded graphite composite phase change material. Appl Energy 91:426-431.

https://doi.org/10.1016/j.apenergy.2011.10.014

Page 14/ 24 
37. Zhang Z, Shi G, Wang S, Fang X, Liu X (2013) Termal energy storage cement mortar containing noctadecane/expanded graphite composite phase change material. Renew Energy 50:670-675. https://doi.org/10.1016/j.renene.2012.08.024

38. Zhou Z, Lin W, Ren H, Ma Z, Yang L et al (2018) Using fuzzy clustering and weighted cumulative probability distribution techniques for optimal design of phase change material thermal energy storage. J. Clean. Prod. 233, 1259-1268. https://doi.org/10.1016/j.jclep ro.2019.05.404 (2019)

\section{Figures}

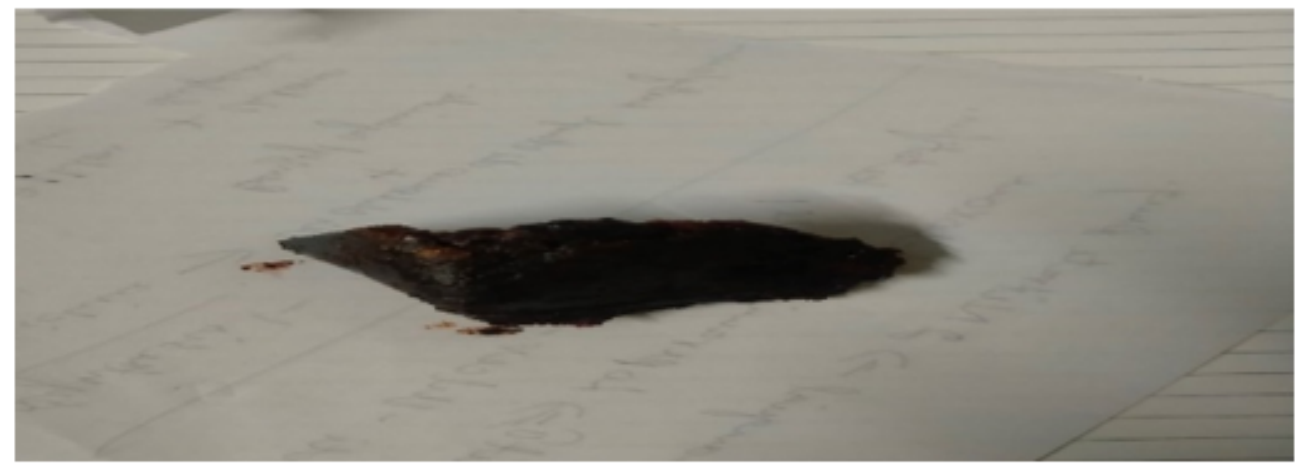

\section{Figure 1}

TRI MYRISTIC+ BLENDED PCM acid from nutmeg

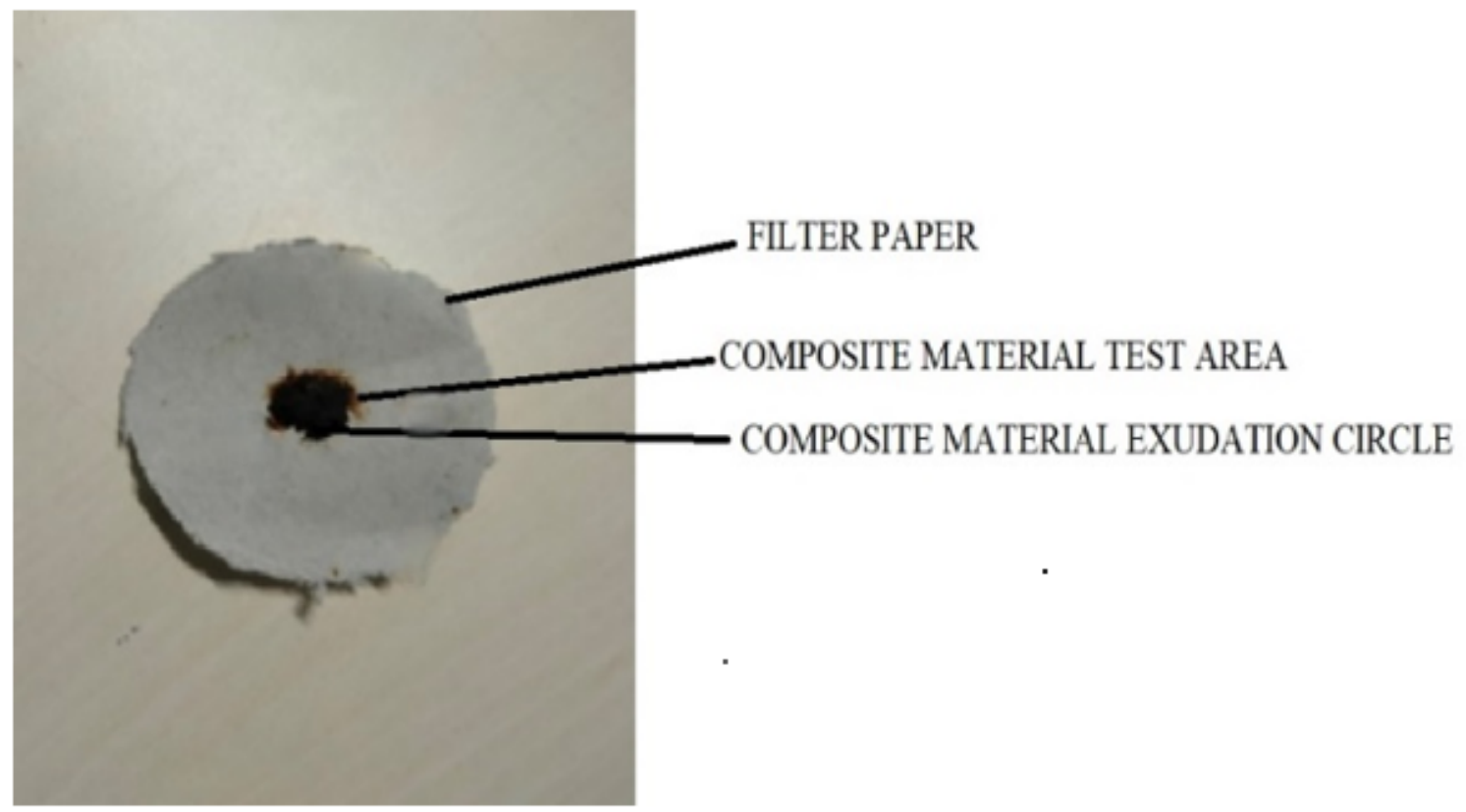

\section{Figure 2}

\section{Diffusion exudation circle test diagram}




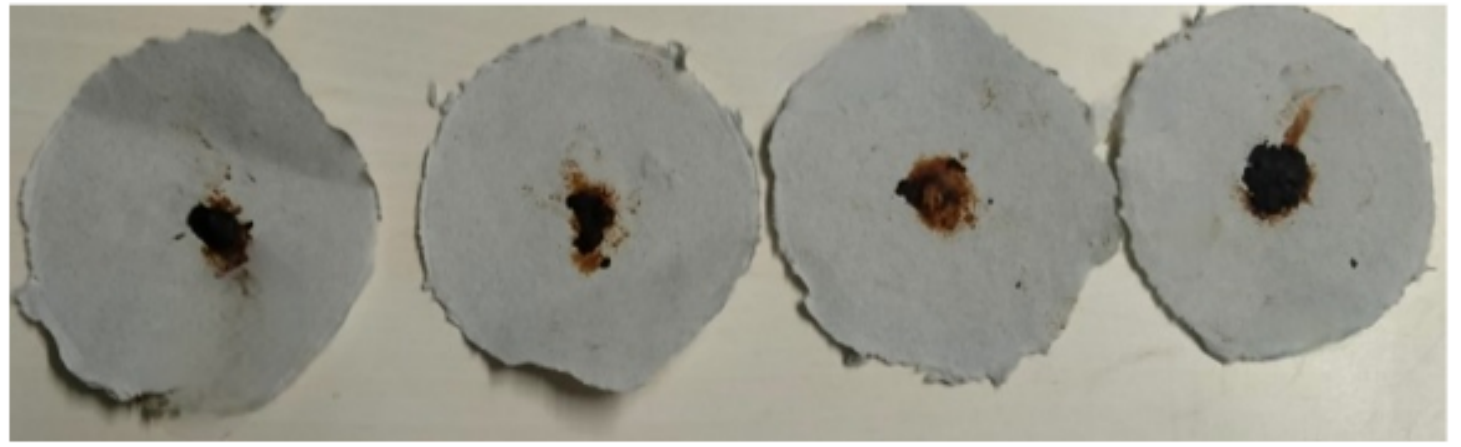

Figure 3

TMA/EV PCM before heat treatment $92 \%, 93 \%, 94 \%, 95 \%$

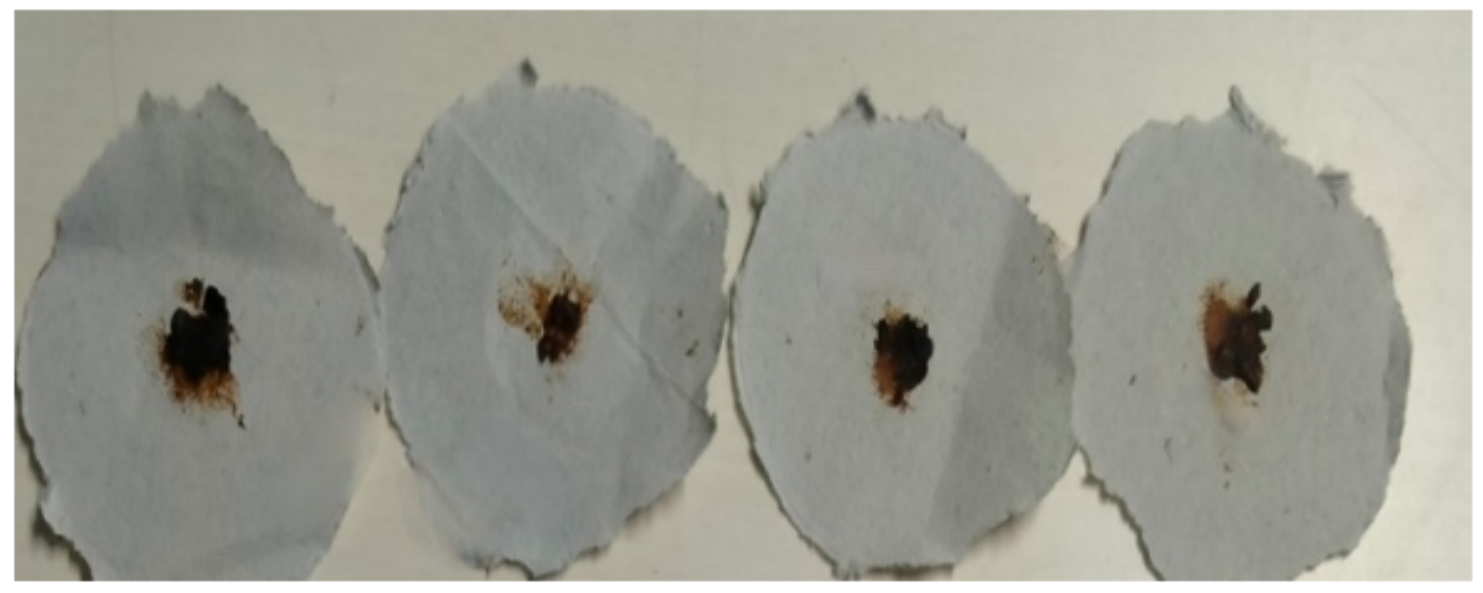

\section{Figure 4}

\section{TMAVEV PCM after heat treatment $92 \%, 93 \%, 94 \%, 95 \%$ :}

outward, the exudation analysis sections were aligned, and the mean was measured. Chart 1 presents a range of fixed leakage proportions as the infiltration resistance evaluation measure. The balance of the extra ordinary exudation ring breadth to the search zone breadth was measured, and the grades were associated with the regular units (Table 1 ) to estimate resistance. All elements not more crucial than the measure indicated that intensity touched identical norms. Figures 3 and 4 display all photos of the developed blended phase change materials (a) before and after the (b) experiment. Oozing was visible in the sample with a $95 \%$ TMA core content. No exudation was recognized with 93\% TMA volume content. Therefore, from Figs. 3 and 4 , the usual significant TMA volume content was approximately 93-94\%. 


\section{(1)SHMAL}
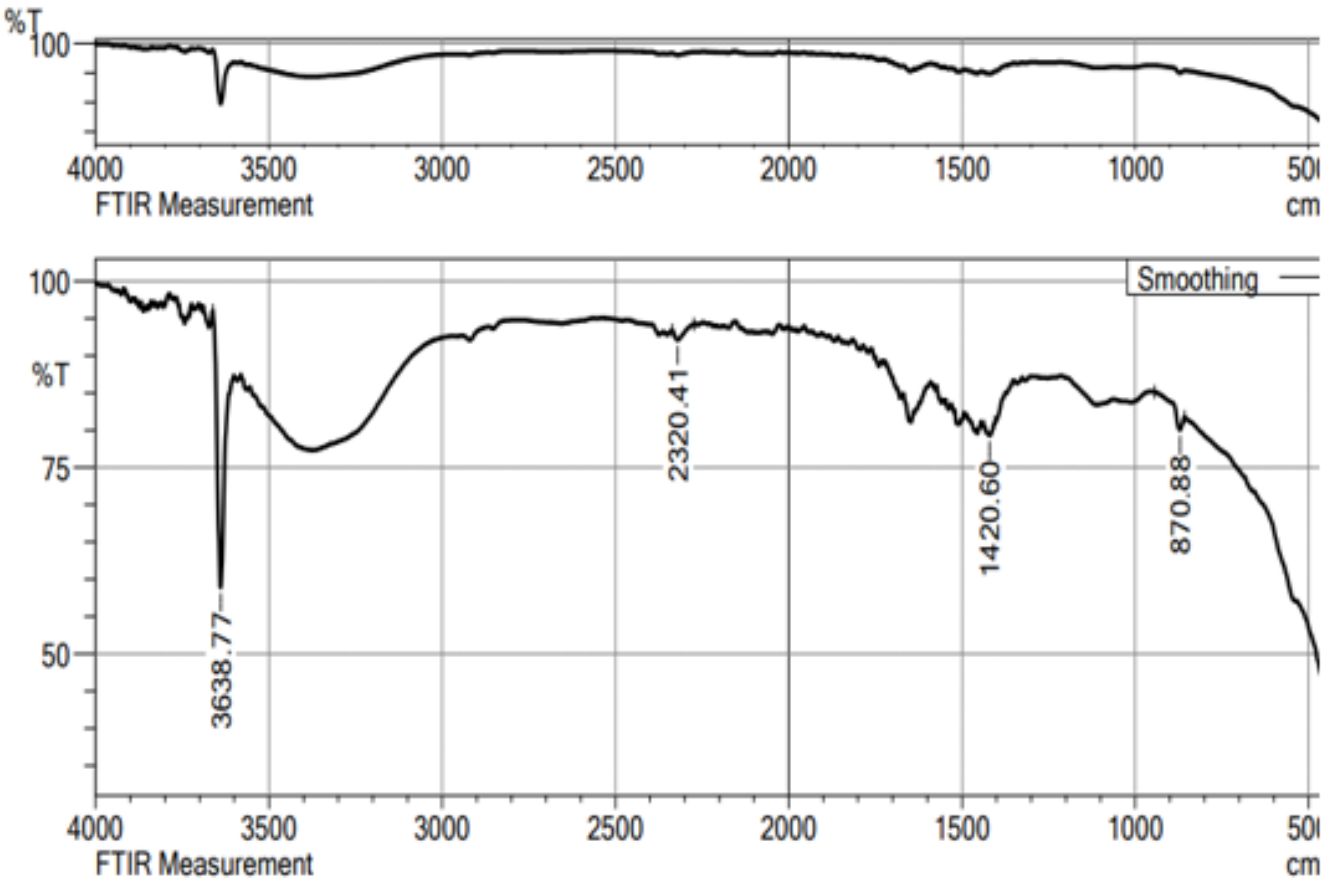

\begin{tabular}{|c|c|}
\hline Item & Value \\
\hline Acquired Date\&Time & $28-07-202112: 47: 40$ \\
\hline Acquired by & System Administrator \\
\hline Filename & C:UsersiDeliDesktop|NRC-FTIR-DATAIFTIR-2021107-July-2021/C-FT|R|Try+Nul+Ver.is \\
\hline \multicolumn{2}{|l|}{ Measure Parameter File } \\
\hline \multicolumn{2}{|l|}{ Report Template } \\
\hline Spectrum name & Smoothing \\
\hline \multicolumn{2}{|l|}{ Sample name } \\
\hline \multicolumn{2}{|l|}{ Sample ID } \\
\hline Option & Instrument Check \\
\hline Comment & FTIR Measurement \\
\hline No. of Scans & 25 \\
\hline Resolution & $2[\mathrm{~cm}-1]$ \\
\hline Apodization & Happ-Genzel \\
\hline
\end{tabular}

\section{Figure 5}

at 870.8 and 2320.41 , it consisted of more polysaccharides, and proteins indicated more periodic compressive strength and flexural strength.

a) Single-bond(c-c) region present between 3639.74-3745.82

b) double bond $(\mathrm{c}=\mathrm{c})$ region present between 1411.92-1650.13

c) triple bond $(\mathrm{c} \equiv \mathrm{c})$ region present between $2000-2300$

d) aliphatic chloro compounds present between $871-900$

e) carboxylate present between 1411-1650.13 
f)aromatic C-H stretch present between $3639.74-3745.82$

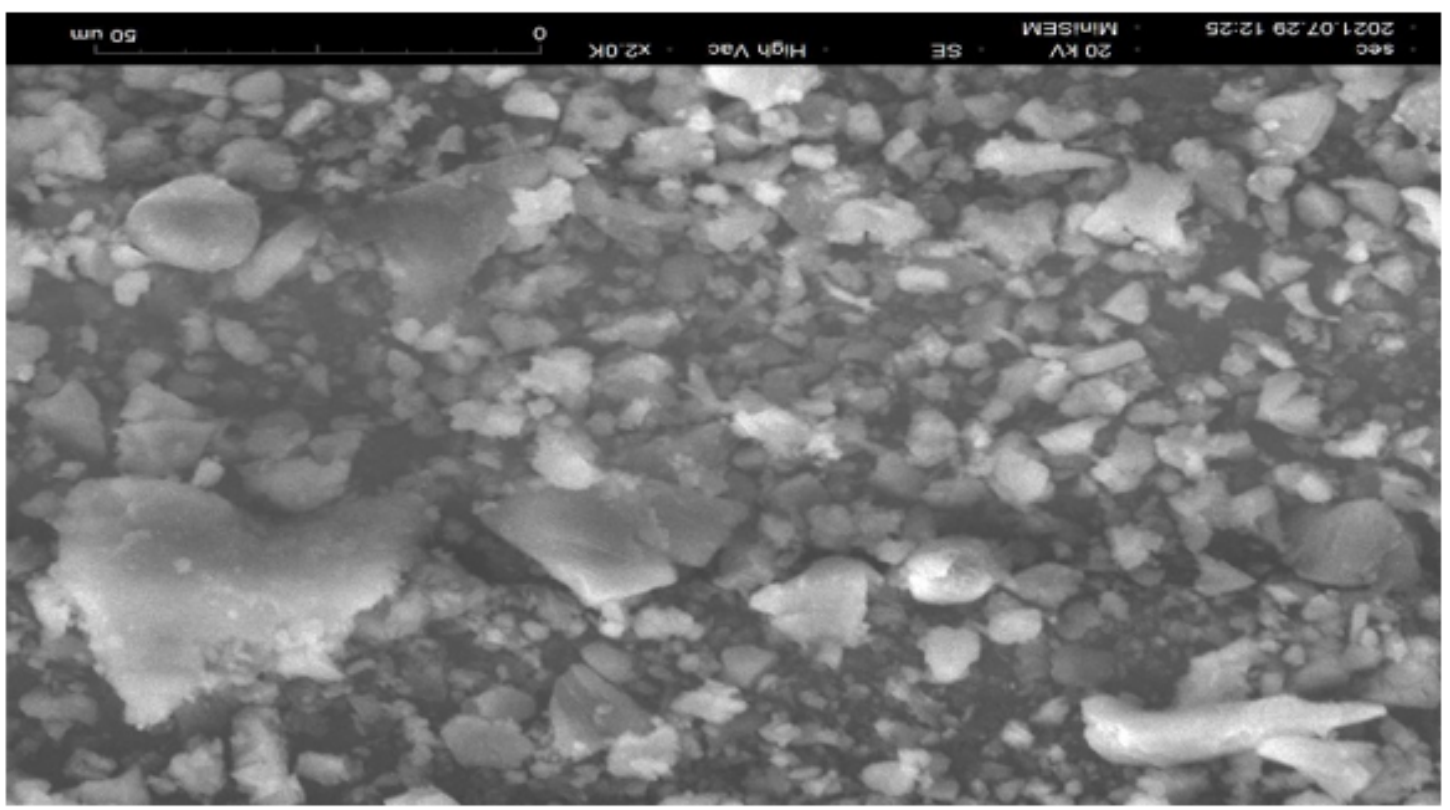

Figure 6

shows closely packed pcm with round structure with $92 \%$

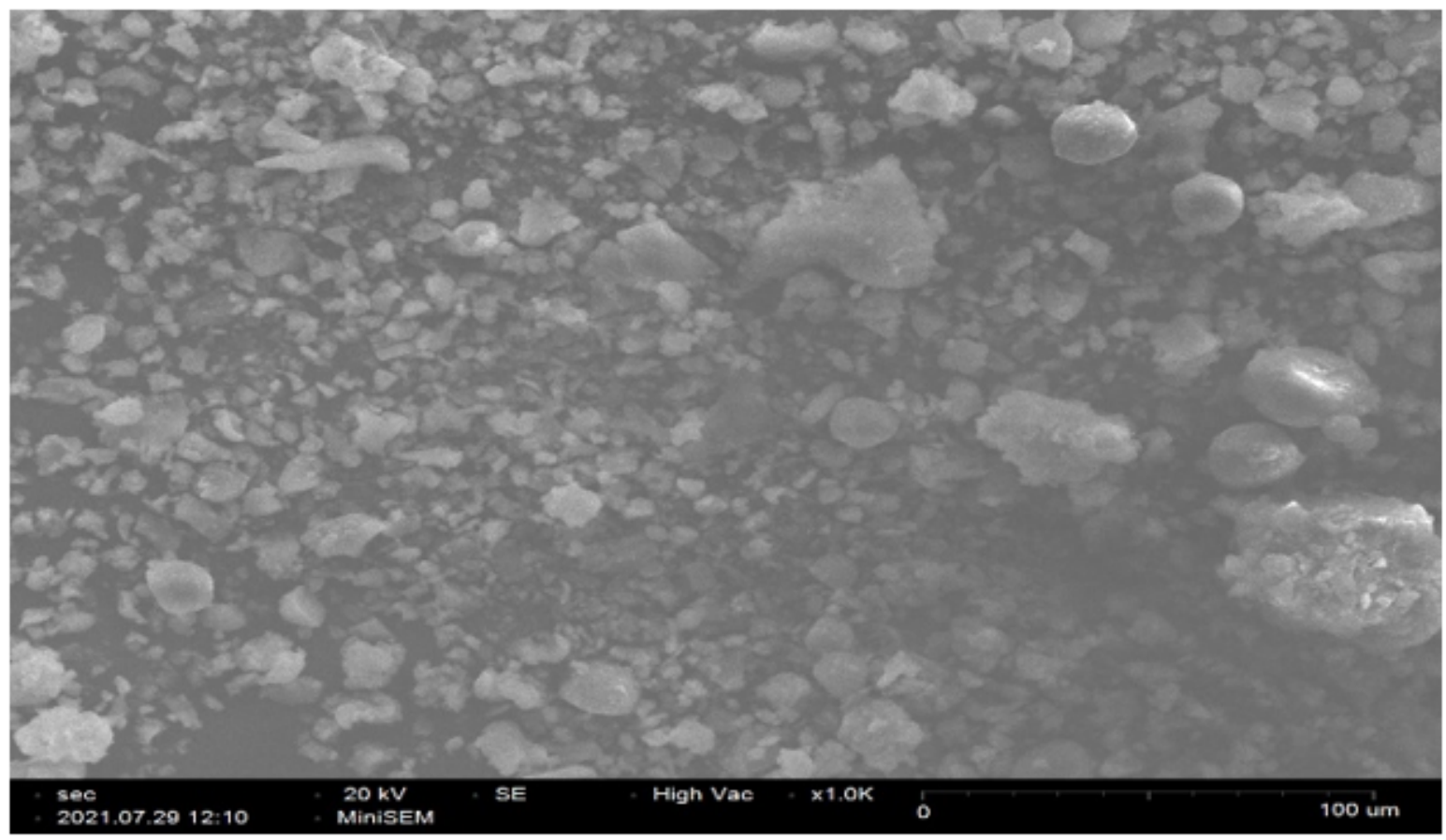

Figure 7

shows closely packed pcm with round structure with $93 \%$ 


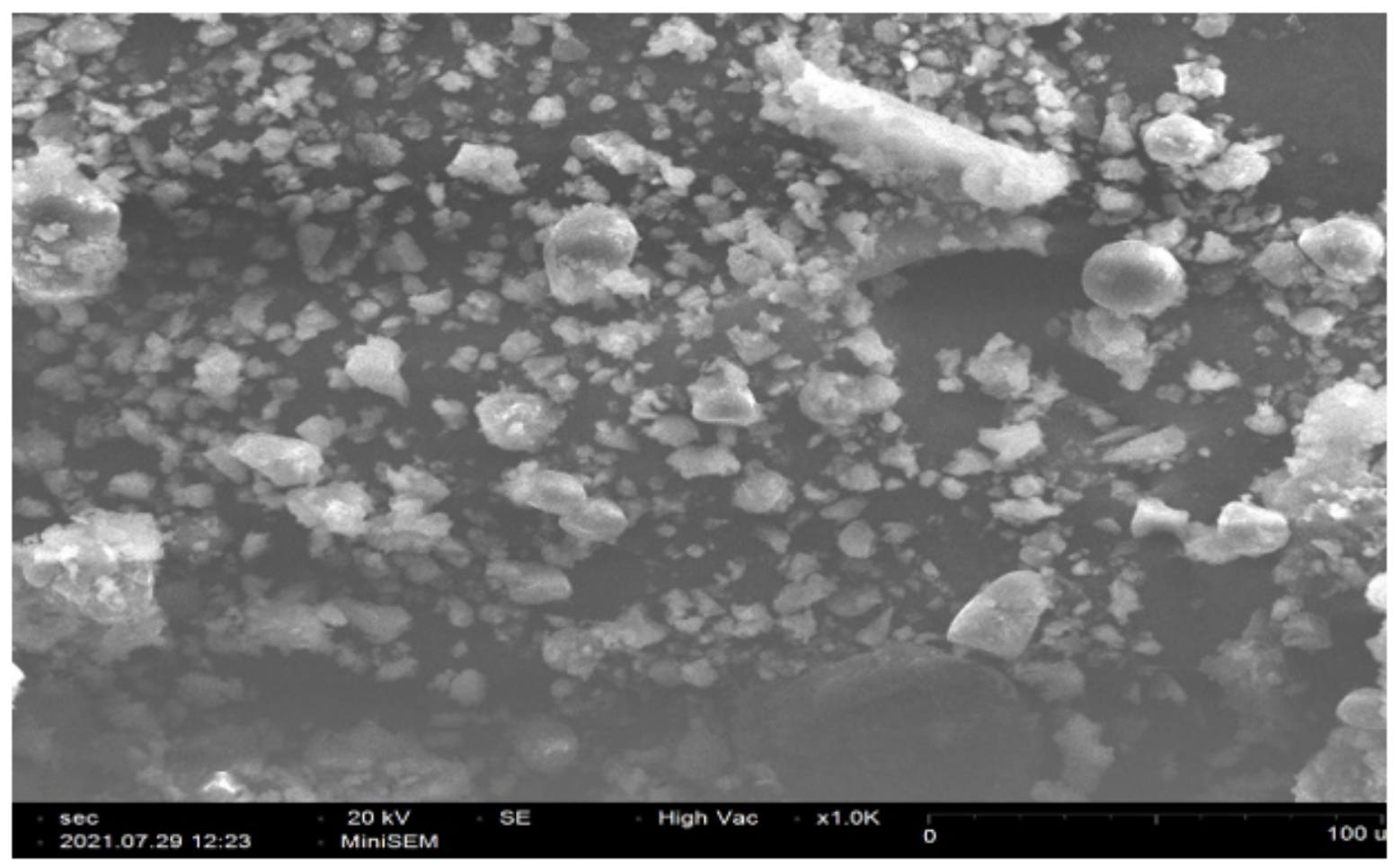

Figure 8

shows losely packed pcm with round structure with $94 \%$ with leakage 


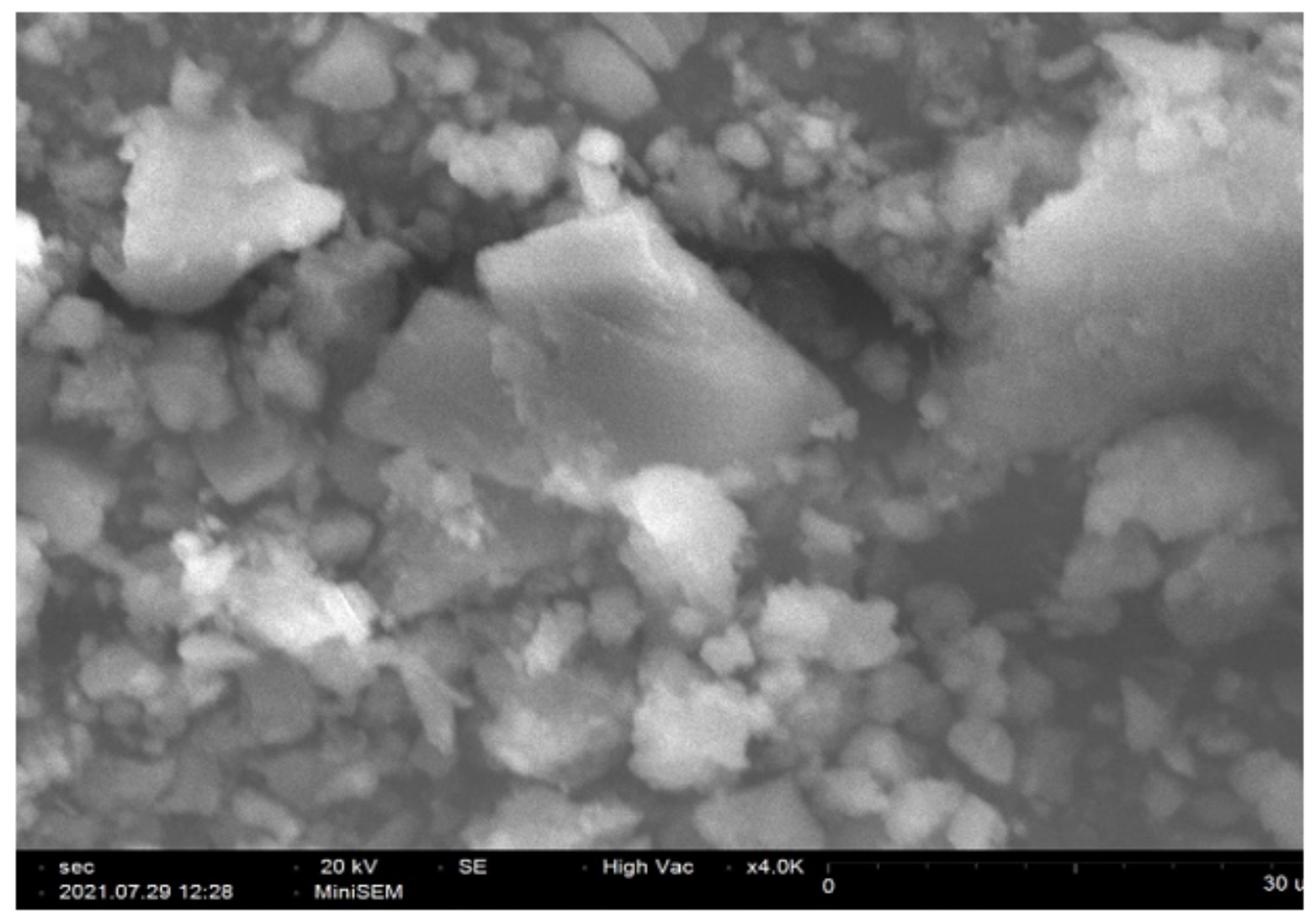

Figure 9

shows closely packed pcm with a round structure of $95 \%$ with leakage 


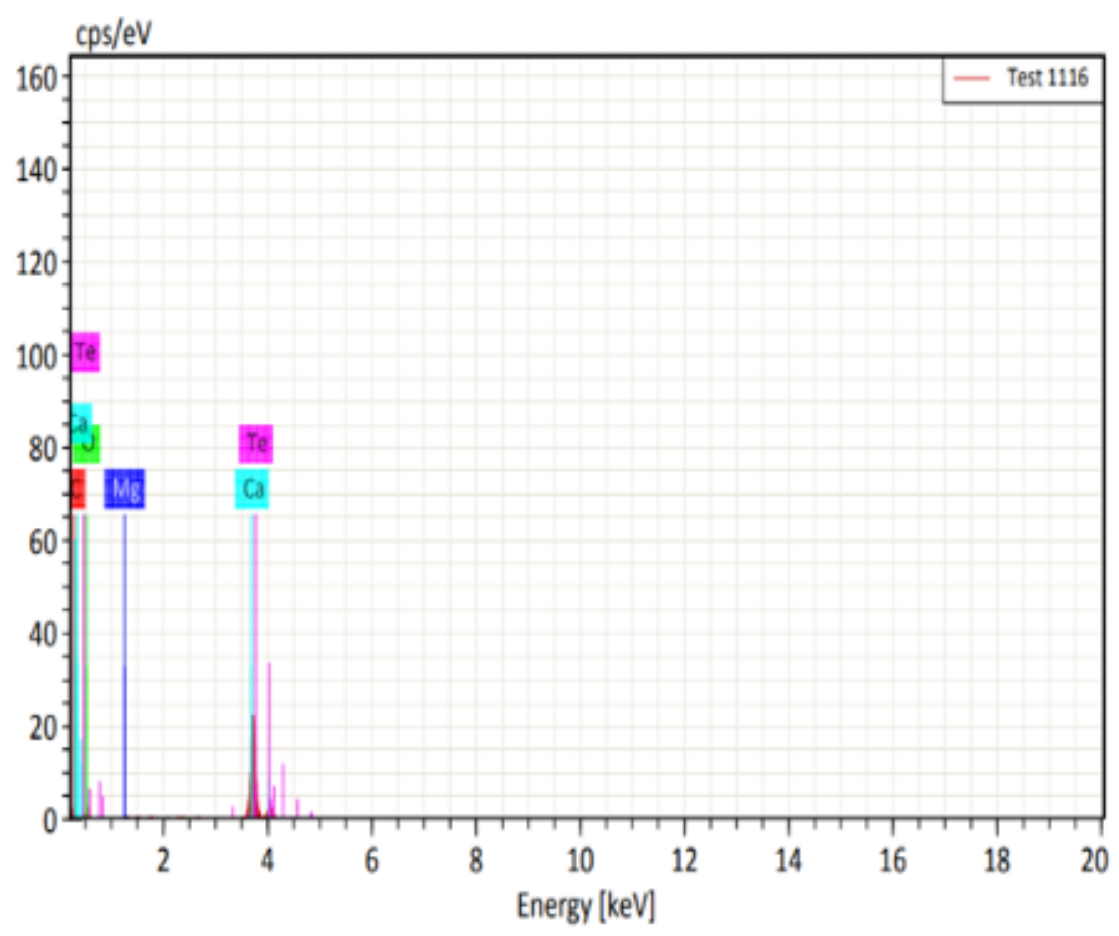

\begin{tabular}{|c|c|c|c|c|c|c|}
\hline Element & At. No. Netto & $\begin{array}{l}\text { Mass } \\
{[\%]}\end{array}$ & $\begin{array}{c}\text { Mass Norm. } \\
{[\%]}\end{array}$ & $\begin{array}{c}\text { Atom } \\
{[\%]}\end{array}$ & $\begin{array}{l}\text { abs. error [\%] } \\
\text { (1 sigma) }\end{array}$ & $\begin{array}{l}\text { rel. error [\%] } \\
\text { (1 sigma) }\end{array}$ \\
\hline Carbon & 66675 & 29.35 & 19.96 & 38.07 & 4.40 & 14.98 \\
\hline Oxygen & 88104 & 42.35 & 28.80 & 41.23 & 6.14 & 14.50 \\
\hline Magnesium & 122240 & 3.61 & 2.46 & 2.32 & 0.26 & 7.06 \\
\hline Calcium & 2083192 & 36.11 & 24.56 & 14.04 & 1.09 & 3.01 \\
\hline \multirow[t]{2}{*}{ Tellurium } & 5254877 & 35.62 & 24.23 & 4.35 & 1.06 & 2.97 \\
\hline & \multicolumn{2}{|c|}{ Sum 147.05} & \multicolumn{2}{|c|}{100.00100 .00} & & \\
\hline
\end{tabular}

\section{Figure 10}

energy dispersive X-ray spectroscopy test it is clear that

Figure 11

shows tri myristic acid with Differential scanning calorimetry(27-31॰C)

Figure 12

shows tri myristic acid+vermiculite with Differential scanning calorimetry(57-59.C) 
shows tri myristic acid+ blended vermiculite with Differential scanning calorimetry(27-31॰C) $(57-59 \circ C)$ \{liquid state\}.

Figure 14

THERMO CONDUCTIVITY VARIATION WITH PACKING DENSITY OF TMA/EV BPCMS

Figure 15

SHOWING DIFFERENT DENSITY OF BPCMS INTRODUCED IN CUBES

Figure 16

SHOWING 12 POINT TEMPERATURE MONITOR FOR DAY TIME MEASURING

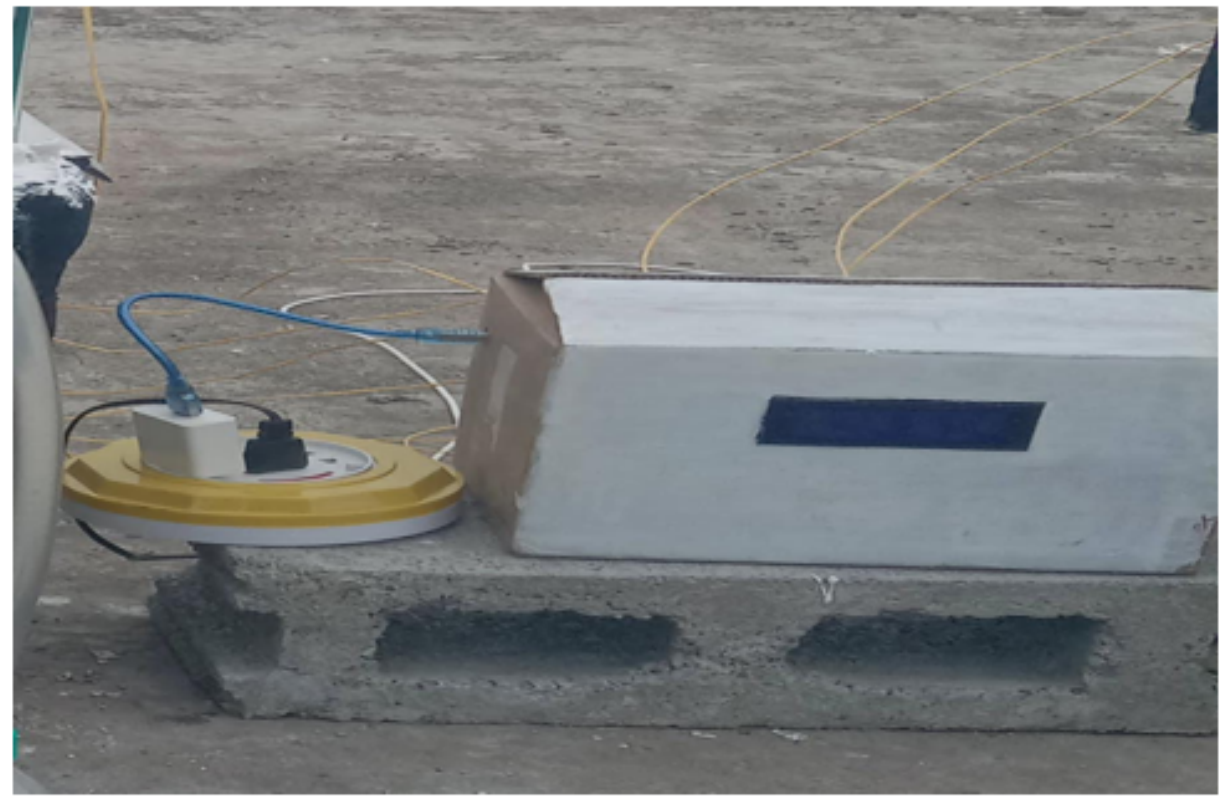

Figure 17

SHOWING 16 POINT TEMPERATURE MONITOR FOR DAY AND NIGHT TIME MEASURING 
Figure 18

SHOWING 16 POINT TEMPERATURE MONITOR FOR DAY AND NIGHT TIME MEASURING WHILE MEASURING THERMAL ENERGY STORAGE AND RELEASING

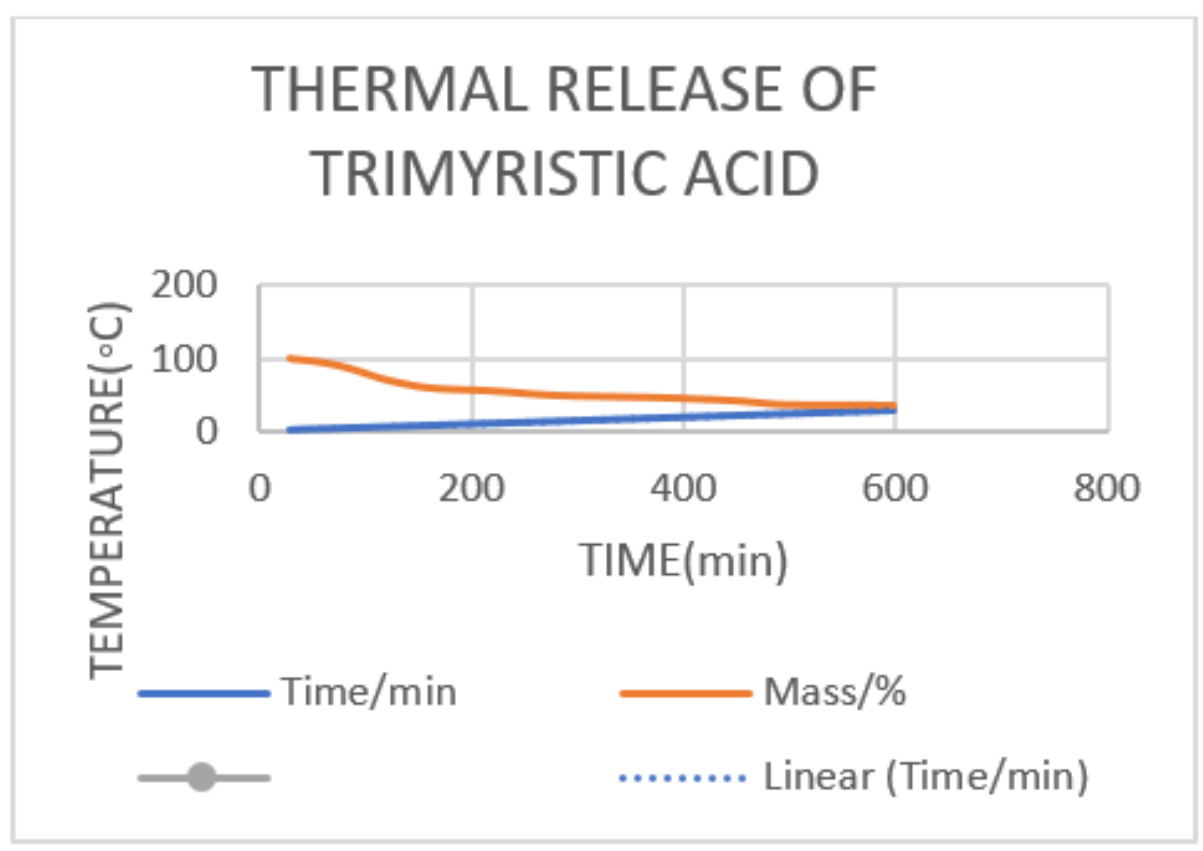

Figure 19

TGA DATA OF THERMAL STORAGE RELEASE CURVES OF TMA BPCMs 


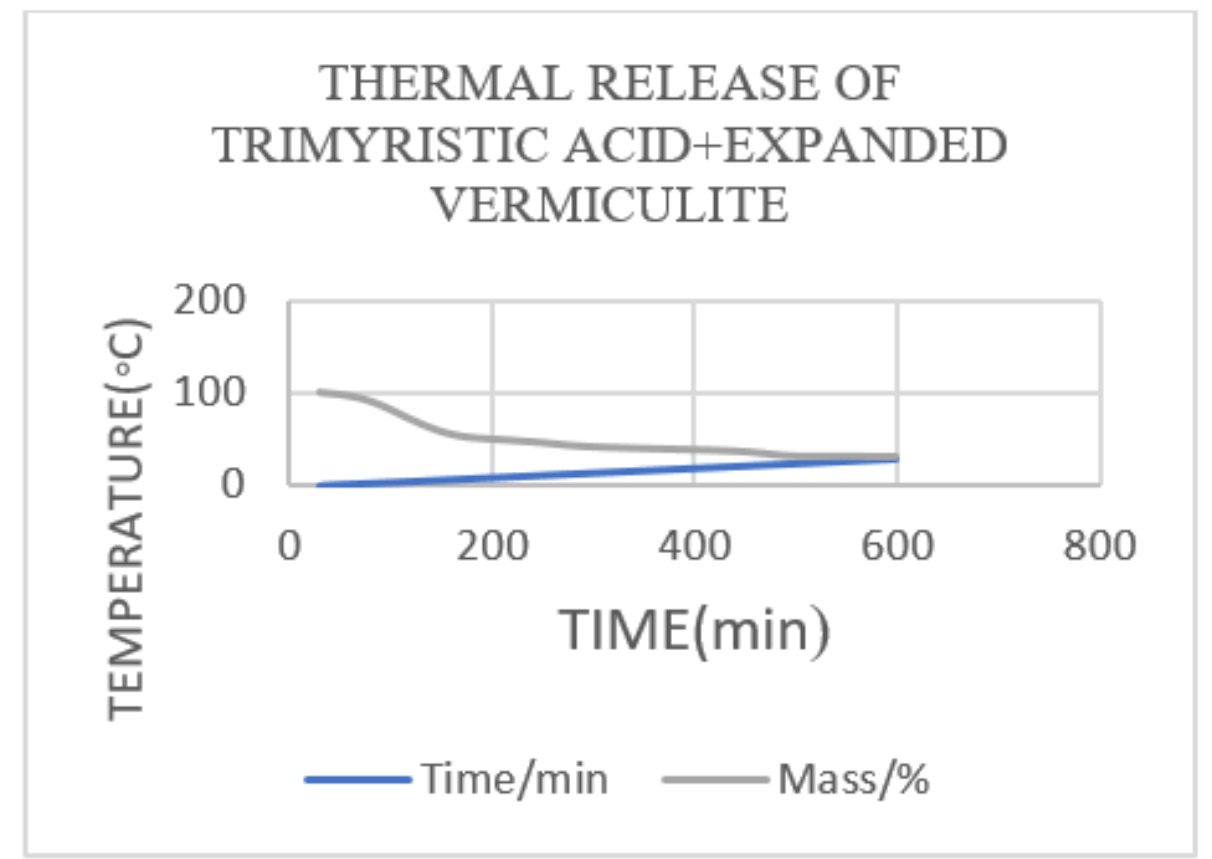

Figure 20

TGA DATA OF THERMAL STORAGE RELEASE CURVES OF TMA/EV BPCMS

Figure 21

TGA DATA OF THERMAL STORAGE \&RELEASE CURVES OF TMAVEV BPCMS 